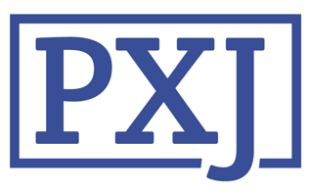

Patient Experience Journal

Volume 7 | Issue 3

Article 11

2020

\title{
Living with cardiovascular disease (CVD): Exploring the biggest challenges for people affected by CVD in the UK, and their use (or not) of online resources
}

\author{
Sarah-Ann Burger \\ Picker Institute Europe \\ Alan J. Poots \\ Picker Institute Europe \\ Anna Perris \\ Picker Institute Europe \\ Helen Crump \\ Picker Institute Europe \\ Helen Thorne \\ Picker Institute Europe
}

See next page for additional authors

Follow this and additional works at: https://pxjournal.org/journal

Part of the Health and Medical Administration Commons, Health Policy Commons, Health Services Administration Commons, and the Health Services Research Commons

\section{Recommended Citation}

Burger S, Poots AJ, Perris A, Crump H, Thorne H, Hughes S, West J. Living with cardiovascular disease (CVD): Exploring the biggest challenges for people affected by CVD in the UK, and their use (or not) of online resources. Patient Experience Journal. 2020; 7(3):83-97. doi: 10.35680/2372-0247.1418.

This Research is brought to you for free and open access by Patient Experience Journal. It has been accepted for inclusion in Patient Experience Journal by an authorized editor of Patient Experience Journal. 


\section{Living with cardiovascular disease (CVD): Exploring the biggest challenges for people affected by CVD in the UK, and their use (or not) of online resources}

\section{Cover Page Footnote}

Author Contributions SAB, AJP, SH, and JW designed the study. SAB and AJP conducted quantitative analyses; $\mathrm{HC}$ conducted qualitative analyses. SAB, AJP, AP, HT interpreted results. AJP and SAB wrote the first iteration of this manuscript; all authors critically revised drafts for content and approved the final version. Acknowledgements We extend our thanks to the interviewees and the survey respondents. If not for their willingness to share their experiences and insights this study could not have been conducted. We thank our colleagues at Picker, especially Susanne Kaesbauer and Amy Tallett, and at the British Heart Foundation, especially Laura Roberts, who provided logistical support to the study. We thank Meltwater for support for social media analysis in scoping work. Thank you to the reviewers of this manuscript for their time and comments. Funding The British Heart Foundation provided funding for this study Ethics All fieldwork complied with the Market Research Society Code of Conduct (2014). Data were stored and protected in compliance with GDPR and ISO procedures. Ethical approval was not required for this project in line with the Health Research Authority guidelines: respondents were not randomised and there was no intervention that changed patient treatment or care pathways. The proposed project was reviewed by an internal ethical board. This article is associated with the Innovation \& Technology lens of The Beryl Institute Experience Framework. (http://bit.ly/ExperienceFramework). You can access other resources related to this lens including additional PXJ articles here: http://bit.ly/PX_InnovTech

Authors

Sarah-Ann Burger, Alan J. Poots, Anna Perris, Helen Crump, Helen Thorne, Sally Hughes, and Jacob West 


\title{
Living with cardiovascular disease (CVD): Exploring the biggest challenges for people affected by CVD in the UK, and their use (or not) of online resources
}

\author{
Sarah-Ann Burger, Picker Institute Europe, sarahann.burger@uq.edu.au \\ Alan J. Poots, Picker Institute Europe, alan.poots@pickereurope.ac.uk. \\ Anna Perris, Picker Institute Europe, Anna.Perris@PickerEurope.ac.uk \\ Helen Crump, Picker Institute Europe, helen.crump@cogency.live \\ Helen Thorne, Picker Institute Europe, Helen.Thorne@warwick.ac.uk. \\ Sally Hughes British Heart Foundation, hughess@bbf.org.uk \\ Jacob West, British Heart Foundation, jacob.west@bhf.org.uk
}

\begin{abstract}
As death rates decrease, people affected by cardiovascular disease (CVD) continue to live with these diseases and the associated challenges, long-term. We aimed to identify the biggest challenges for people affected by CVD in the UK and explore the sources of support and information used to help manage conditions, to inform future service provision. An online questionnaire was sent and advertised to people over 16 years old in the UK self-identifying as affected by CVD (living with CVD, had risk factors, or a carer). There were 13,885 responses. The top five challenges were: feeling down, sad, or depressed; making changes to the way or amount of exercise; anxiety, fear, and uncertainty about the future; having one member of staff to speak to about all aspects of care; and being given information on the side effects of medications. Key challenges were not restricted to a particular condition, indicated by minimal variation between types of CVD. One-quarter of respondents indicated they do not use online resources or digital technologies to help manage their health. The volume and inconsistency of online sources were reported as barriers to using these. The results highlight the psychological and physical consequences of living with CVD. Fragmented care and variable access to information and support further compound these issues. Providing holistic care needs attention; the acknowledgement of psychological needs and access to support, alongside physical challenges is necessary. Stakeholders in healthcare and information technology should work together to ensure online information and support is clear, consistent, and reliable.
\end{abstract}

\section{Keywords}

Continuum of care, surveys and questionnaires, cardiovascular diseases, emotions, health resources

\section{Introduction}

There are an estimated 7.4 million people living with cardiovascular disease (CVD) in the UK. ${ }^{1}$ Of these, approximately 2.3 million people live with coronary heart disease, over 1.3 million are affected by stroke, and 620,000 live with an inherited heart-related condition. In 1961, CVD was attributed to more than half of all deaths in the UK; however, mortality rates have declined by $75 \%$ between 1969 and 2017. ${ }^{1}$ While lower mortality rates are a positive outcome, progress in reducing premature deaths from CVD means that there are now more people living with these diseases long term and facing challenges associated with these, including an increase in treatment and hospitalisation. ${ }^{2}$ There have been calls for policy and practice in the UK to respond to the "shift in relative burden from mortality towards morbidity." 3 This is important to ensure provision of sustainable services in the future.

People living with CVD, and those providing care and support to them, experience a wide range of challenges related to the physical and psychosocial impacts of CVD, daily living, and clinical management. There is a wealth of literature examining these challenges; however, it is typically focused on particular needs and conditions. For example, exercise is challenging for people affected by peripheral arterial disease, ${ }^{4-6}$ congenital heart disease, ${ }^{7,8}$ and coronary heart disease. ${ }^{9}$ Mental well-being and depression is challenge for people affected by congenital heart disease ${ }^{10}$ and heart failure. ${ }^{11}$ Self-care is difficult for people with heart failure, ${ }^{12,13}$ congenital heart disease, ${ }^{14,15}$ and psychological impacts and loneliness affect people who suffered acute events ${ }^{16}$ and stroke. ${ }^{17}$ The psychological needs of people affected by ischaemic heart

Patient Experience Journal, Volume 7, Issue 3-2020

(C) The Author(s), 2020. Published in association with The Beryl Institute

Downloaded from www.pxjournal.org 
disease ${ }^{18}$ and ischaemic stroke, ${ }^{19}$ and social support requirements for people affected by coronary heart disease have been investigated. ${ }^{20}$ There are examples of literature discussing several conditions, but with a particular focus, for example stress, ${ }^{21}$ self-care, ${ }^{22}$ or seeking to derive educational intervention. ${ }^{23}$ Further, where all CVD types are considered, attention is focused on prevention, ${ }^{24}$ call to action for treatment, ${ }^{25}$ or a hospitalised group, ${ }^{23}$ rather than the experiences of people living with CVD. There is a gap in understanding the most prominent challenges and priorities for people affected by CVD. While the literature suggests overlapping challenges for people living with different conditions, a comprehensive examination of challenges across all groups is lacking.

Self-care and management is a key aspect of living with CVD. ${ }^{12}$ Many self-care interventions aim to empower patients by improving their understanding of their condition, to take responsibility and control of their own health, and increase self-efficacy. ${ }^{22}$ Access to online resources (e.g., websites), digital technology (e.g., wearable devices), or sources of support (e.g., support groups) could be a positive addition to the tools available to patients and carers to manage their wellbeing. ${ }^{24}$ However, there are concerns over the privacy and accuracy of digital technologies for the management of health. ${ }^{25-27}$ The 'information revolution' has allowed people to have a greater and more immediate connection to any information they could want as a consumer. Yet, little is known about what resources people access or seek out to address their unmet needs, or assist with self-management or self-care.

The overarching aim of this study was to examine the key challenges and unmet needs of people affected by CVD in the UK and to identify the resources or sources of support that they use to help manage their health. In particular, the study explored respondents' use of online or digital technologies, and other non-medical resources. The research questions were:

1. What are the biggest challenges and unmet needs of people affected by CVD in the UK?

2. What, if any, online resources and digital technologies do people affected by CVD use to help manage their condition?

\section{Methods}

\section{Questionnaire Design}

A questionnaire was developed to understand the key challenges faced by people affected by CVD, and to capture information on the resources they use for selfmanagement of their disease. Questionnaire content was informed by desk and qualitative research. This included a rapid review of existing literature, a social media analysis for mentions of CVD, and focus groups and semi- structured interviews with 45 people affected by CVD. Five focus groups with 37 participants were conducted, one with each of the following condition groups: congenital heart disease; inherited cardiovascular conditions; acute events, such as heart attack or stroke; people living with the known risk factors of heart disease; and people who have undergone surgery to address CVD. Eight telephone interviews were conducted with people living with heart failure, as this cohort were deemed less able to travel to focus groups. Participants were recruited by advertisements posted online and local print media, social media, and promoted by the British Heart Foundation (BHF) to their existing contacts and communities. A semi-structured topic guide sought to capture in depth information about the experiences and needs of people living with CVD, including support and information needs. Thematic analysis identified people's needs, the resources they draw on or would like more of, and the extent to which participants have needs and requirements in common.

A list of 35 key challenges was derived from the desk research and qualitative data (Appendix A), and grouped into three broad themes: physical challenges, emotional or psychological challenges, and medical, information or support challenges. This was achieved via working meetings between the project team iterating designs that synthesised information into a useable number of items. The questionnaire was designed to capture the extent to which participants experienced a specific challenge, their need for help with that challenge; and whether they received support to address that challenge (need met), if required. It captured participants' use of digital, technological or alternative resources in general and to help manage their condition, and demographic questions. Overall, the questionnaire contained 26 questions including demographics (Table 1).

Questions were scripted into Snap Surveys 10 and implemented via Snap Webhost. The landing page provided information about the study and outlined who was eligible to participate. Contact details at the British Heart Foundation (BHF) were provided for concerns about health and a separate contact for queries about the survey. Respondents were asked if 'partial data' could be used if they did not complete the survey or press submit at the end of the survey.

\section{Sampling}

Anyone over the age of 16 years and living in the UK affected by a heart or circulatory condition or their risk factors, including friends or family (referred to as carers), was eligible to participate.

In August 2018, approximately 250,000 people on the BHF's mailing lists were sent an email with information about the survey, inviting them to participate and included 
a hyperlink to the survey. The mailing list included all individuals within databases held by the BHF, representing people who had opted-in to communications by email, constituted the insight panel, or comprised a patient network group. Members include the public, event participants, and patients. Social media adverts, posted on Facebook and Health-Unlocked, included information about the survey and a hyperlink.

Responses logged were fully anonymous. The questionnaire was in field for four weeks and closed in September 2018.

\begin{abstract}
Analysis
Data were extracted from Snap Webhost and imported into SPSS v23 for analysis. Data were cleaned, by (i) removing partial responses for those people who did not consent for their partial data to be used; and (ii) removing partial responses with no data for the questions asking about specific challenges or needs, as the survey relied on information from these questions for routing.

The data were analysed using descriptive statistics, bivariate analysis, and correlations. Frequency tables were produced to display responses to all survey questions. The top five challenges were identified based on the combined
\end{abstract}

proportion of people reporting a 'bigh' or 'moderate need for help’ with a specific challenge, ranked by percentage of responses (see Table 1). This was repeated by type of CVD (demographic variable) to examine the top challenges for each condition.

'Unmet needs' were identified based on the proportion of participants who responded they received 'no belp at all with the specific challenge (see Table 1). Only those respondents who indicated a 'bigh...' or 'moderate need for belp' with a specific challenge were asked to report whether they received any support or help to manage that challenge, thus base sizes vary.

To determine if there was a relationship between the identified top five challenges and the other 35 challenges asked in the survey, Kendall's tau-b correlations were calculated and assessed against a threshold of 0.6.

Bivariate analyses were used to examine the relationship between categorical demographic variables (including age, gender and type of CVD), and each of the 35 listed challenges, and use of technology. Chi-square statistics were used to judge the level of association between these variables. Z-tests were conducted to explore differences

\section{Table 1. Survey question areas and response categories}

\begin{tabular}{|c|c|}
\hline Question & Response Categories \\
\hline $\begin{array}{l}\text { Need for help with a specific } \\
\text { challenge } \\
\text { For each item, please select the box that } \\
\text { best describes if and how much you bave } \\
\text { needed help (if at all) as a result of being } \\
\text { affected by a heart \& circulatory condition } \\
\text { or their risk, factors }\end{array}$ & $\begin{array}{l}35 \text { items/challenges, asked to all } \\
\text { - This was not a problem for me / I have not needed help } \\
\text { - This was a problem for me and I have had a low need for help } \\
\text { - This was a problem for me and I have had a moderate need for help } \\
\text { - This was a problem for me and I have had a high need for help }\end{array}$ \\
\hline $\begin{array}{l}\text { Received help for their self- } \\
\text { identified needs } \\
\text { If you bave needed help or support, did you } \\
\text { receive the belp you needed? }\end{array}$ & $\begin{array}{l}\text { Asked of those people indicating they needed help with specific challenge (variable } \\
\text { number of items, depending on answer to previous question) } \\
\text { - Not applicable } \\
\text { - Not at all (I have not received any help) } \\
\text { - Yes, to some extent } \\
\text { - Yes, definitely (I have received all the help I needed) }\end{array}$ \\
\hline $\begin{array}{l}\text { What they would have liked to } \\
\text { have been done differently if their } \\
\text { needs were unmet }\end{array}$ & $\begin{array}{l}\text { Asked of those who received no or little help with specific challenge } \\
\text { (variable number of items, depending on answer to previous question) } \\
\text { - Open - freetext }\end{array}$ \\
\hline $\begin{array}{l}\text { Anything exceptional that helped } \\
\text { address their needs }\end{array}$ & $\begin{array}{l}\text { Asked of those who received help with specific challenge } \\
\text { (variable number of items, depending on answer to previous question) } \\
\text { - Open - freetext }\end{array}$ \\
\hline $\begin{array}{l}\text { Use of digital resources and } \\
\text { technology in general, and to } \\
\text { help manage health }\end{array}$ & Multi-choice \\
\hline
\end{tabular}


Table 2. The top five challenges as identified and ordered by the proportion of people reporting a 'high or moderate need for help' and an indication of help received

\begin{tabular}{|l|l|l|}
\hline A. Top five challenges & $\begin{array}{l}\text { B. Need for help } \\
\text { Proportion indicating a 'high or moderate } \\
\text { need for help' }\end{array}$ & $\begin{array}{l}\text { C. Unmet need } \\
\text { Proportion who received 'no help or } \\
\text { support at all' (of those indicating a 'high' } \\
\text { or 'moderate need for help') }\end{array}$ \\
\hline $\begin{array}{l}\text { 1. Feeling down, sad, or } \\
\text { depressed }\end{array}$ & $24 \%(2965 / 12,312)$ & $36 \%(829 / 2276)$ \\
\hline $\begin{array}{l}\text { 2. Making changes to the way } \\
\text { or amount of exercise }\end{array}$ & $24 \%(3118 / 13,261)$ & $29 \%(639 / 2229)$ \\
\hline $\begin{array}{l}\text { 3. Anxiety, fear, and uncertainty } \\
\text { about the future }\end{array}$ & $23 \%(2781 / 12,338)$ & $37 \%(785 / 2143)$ \\
\hline $\begin{array}{l}\text { 4. Having one member of staff } \\
\text { to speak to about all aspects of } \\
\text { care }\end{array}$ & $20 \%(2060 / 10,579)$ & $47 \%(841 / 1786)$ \\
\hline $\begin{array}{l}\text { 5. Being given information on } \\
\text { the side effects of medications }\end{array}$ & $19 \%(2031 / 10,646)$ & $46 \%(808 / 1777)$ \\
\hline
\end{tabular}

between individual pairs, or response options within the bivariate analyses.

Freetext data from open-ended questions were examined using thematic analysis: grouping responses into broad categories, that were iteratively derived.

\section{Patient and Public Involvement and Engagement} The BHF commissioned the project to inform their strategy development, which was advised by a Patient and Public Advisory Group. This group commented on the study design and the survey content circulated to the BHF before launch, with changes to phraseology and question format made as a result. They advised on dissemination of the results, including to study respondents and the wider patient community, which has taken place via press releases and social media activity as part of the BHF's strategy.

\section{Results}

As the questionnaire did not force response, the number of respondents to each question varied as not everyone answered every question. After cleaning the data set there were 13,885 useable responses, of which more than 9000 provided details on demography and use of digital resources. The following section outlines the key challenges reported, and the sources of support sought. Respondent characteristics are available as Appendix B.

\section{Challenges}

The top five challenges were identified by the proportion of people stating they had a 'bigh or moderate need for help' with a specific challenge (Table 2). The largest proportion of respondents reported a challenge relating to 'feeling down, sad, or depressed.' Other key challenges related to exercise, uncertainty about the future, continuity of care, and access to information about potential side-effects of medications. Of those respondents indicating that they had a 'high or moderate need for help' with a challenge, significant percentages were not receiving the help they needed. For example, $47 \%(841 / 1786)$ of respondents who reported a challenge relating to 'Having one member of staff to speak to about all aspects of care' indicated that they had received 'no help or support at all' for this.

Exploration of the top five challenges by CVD condition found only some differences in ordering and a few instances of a different challenge presenting in their respective top five. Table 3 presents the top five challenges for each CVD condition. Where a challenge is different from the overall top five, that challenge is described in the table.

The overall top five challenges are statistically significantly correlated with a number of the other 35 challenges asked in the questionnaire. For ease, Table 4 only presents those challenges that correlate with the top five challenges at a threshold of 0.6 using Kendall's tau-b correlation. For example, 'feeling down, sad or depressed' was associated with other challenges linked to mental health and a feeling of needing to hide being unwell. The challenge of 'being given information on the side effects of medications' was associated with other unmet informational needs.

\section{Resources \& Support Used}

While $93 \%$ (9175/9846) of respondents reported that they use online resources or digital technologies in their day-today life, only 22\% (2224/9961) of respondents regularly used online resources specifically for their health, and 54\% occasionally used them (5423/9961). These respondents were asked a multi-response follow-up question on reasons for usage (Appendix C1). The most common 
Table 3. The top five challenges by cardiovascular disease condition are identified and ordered by the proportion of people reporting a 'high or moderate need for help' with a challenge. (Numbered items indicate the challenge and rank in the overall top five. A full description of a challenge is provided when different to overall top five, in italics.)

\begin{tabular}{|c|c|c|c|c|c|c|c|c|}
\hline $\begin{array}{l}\text { Order of } \\
\text { challenges } \\
\text { for } \\
\text { condition } \\
\text { type }\end{array}$ & $\begin{array}{l}\text { Congenital } \\
\text { Heart } \\
\text { Disease }\end{array}$ & $\begin{array}{l}\text { Arrhythmia } \\
\text { s }\end{array}$ & $\begin{array}{l}\text { Inherited } \\
\text { Heart } \\
\text { Disease }\end{array}$ & $\begin{array}{l}\text { Disease of } \\
\text { the heart } \\
\text { valves }\end{array}$ & $\begin{array}{l}\text { Coronary } \\
\text { Heart } \\
\text { Disease }\end{array}$ & $\begin{array}{l}\text { Heart } \\
\text { Failure }\end{array}$ & Stroke & $\begin{array}{l}\text { Peripheral } \\
\text { Arterial } \\
\text { Disease }\end{array}$ \\
\hline First & 3. Anxiety & 2. Exercise & $\begin{array}{l}1 . \\
\text { Depressed }\end{array}$ & 3. Anxiety & 2. Exercise & 2. Exercise & 3. Anxiety & 2. Exercise \\
\hline Second & $\begin{array}{l}1 . \\
\text { Depressed }\end{array}$ & $\begin{array}{l}1 . \\
\text { Depressed }\end{array}$ & 3. Anxiety & 2. Exercise & 3. Anxiety & $\begin{array}{l}\text { Feeling weak/ } \\
\text { lack of energy }\end{array}$ & 2. Exercise & 3. Anxiety \\
\hline Third & 2. Exercise & 3. Anxiety & 2. Exercise & $\begin{array}{l}\text { Feeling weak/ } \\
\text { lack of energy }\end{array}$ & $\begin{array}{l}1 . \\
\text { Depressed }\end{array}$ & 3. Anxiety & $\begin{array}{l}1 . \\
\text { Depressed }\end{array}$ & $\begin{array}{l}\text { 4. Single } \\
\text { contact }\end{array}$ \\
\hline Fourth & $\begin{array}{l}\text { Feeling weak/ } \\
\text { lack of energy }\end{array}$ & $\begin{array}{l}\text { 4. Single } \\
\text { contact }\end{array}$ & $\begin{array}{l}\text { Receiving } \\
\text { consistent } \\
\text { information } \\
\text { from } \\
\text { bealthcare } \\
\text { professionals }\end{array}$ & $\begin{array}{l}1 . \\
\text { Depressed }\end{array}$ & $\begin{array}{l}\text { 4. Single } \\
\text { contact }\end{array}$ & $\begin{array}{l}1 . \\
\text { Depressed }\end{array}$ & $\begin{array}{l}\text { 4. Single } \\
\text { contact }\end{array}$ & $\begin{array}{l}\text { 5. Side- } \\
\text { effects }\end{array}$ \\
\hline Fifth & $\begin{array}{l}\text { 4. Single } \\
\text { contact }\end{array}$ & $\begin{array}{l}\text { 5. Side- } \\
\text { effects }\end{array}$ & $\begin{array}{l}\text { Maintaining a } \\
\text { good quality of } \\
\text { life }\end{array}$ & $\begin{array}{l}\text { 4. Single } \\
\text { contact }\end{array}$ & $\begin{array}{l}\text { 5. Side- } \\
\text { effects }\end{array}$ & $\begin{array}{l}\text { Work around } \\
\text { the home (e.g. } \\
\text { cleaning, } \\
\text { cooking, } \\
\text { eating, } \\
\text { washing) }\end{array}$ & $\begin{array}{l}\text { Maintaining a } \\
\text { good quality of } \\
\text { life }\end{array}$ & $\begin{array}{l}\text { Maintaining a } \\
\text { good quality of } \\
\text { life }\end{array}$ \\
\hline \multicolumn{9}{|c|}{$\begin{array}{l}\text { Top ranked challenges for overall dataset } \\
\text { 1. Depressed: Feeling down, sad, or depressed } \\
\text { 2. Exercise: Making changes to the way or amount of exercise } \\
\text { 3. Anxiety: Anxiety, fear, and uncertainty about the future } \\
\text { 4. Single contact: Having one member of staff to speak to about all aspects of care } \\
\text { 5. Side-effects: Being given information on the side effects of medications }\end{array}$} \\
\hline
\end{tabular}

response was 'Websites to get information about the condition or diagnosis' (87\%, 6073/7469), followed by 'Resources to help with general health e.g., healthy eating, recipe websites or tips to stay in shape' $(65 \%, 4882 / 7469)$, 'Websites to get information on how to manage the condition at home' $(55 \%, 4124 / 7469)$, and 'Websites to get information about different treatment options' (55\%; 4031/7469).

Nearly a quarter of respondents never used online resources specifically for their health $(23 \%$; 2314/9961). Male respondents $\left(\mathrm{X}^{2} 83.94\right.$ (2) $\mathrm{p}<0.001$; Appendix C2) and respondents over 65 years $\left(\mathrm{X}^{2} 307.02\right.$ (12) $\mathrm{p}<0.001$; Appendix C2) were significantly less likely to use online resources to help manage their health. For those respondents who indicated that they do not use online or digital resources to get information or help manage their health or condition, the main reasons can be summarised as concerns about information quality (inconsistency across websites $(41 \%$; 1872/4553), lack of trust $(20 \%$;
$921 / 4553)$, quantity being overwhelming (18\%; 839/4553), and privacy concerns $(15 \% ; 666 / 4553))$; and motivations of the individual (not needing more information $(28 \%$; $1273 / 4553)$, not wanting any $(6 \% ; 268 / 4553)$, and being scared by the information $(14 \% ; 652 / 4553))$. Ability to use and access to digital technologies were infrequently selected (Appendix C3). Free-text comments from those who selected 'Other' $(10 \%$; 453/4553) suggested that they prefer to seek information or advice from medical professionals in person, rather than online.

One-third $(33 \%, 3277 / 9875)$ of respondents stated they use digital technologies or devices, such as wearable technologies (e.g., pedometers), to help them manage their health or condition. The $67 \%(6598 / 9875)$ of people who selected that they do not use any digital technologies or devices were asked why in a follow-up question (Appendix 
Table 4. Kendall's tau-b correlations of the top five challenges with other challenges in questionnaire, where threshold of 0.6 or greater.

\begin{tabular}{|c|c|c|c|c|c|}
\hline & $\begin{array}{l}\text { 1. Feeling } \\
\text { down, sad, or } \\
\text { depressed }\end{array}$ & $\begin{array}{l}\text { 2. Making } \\
\text { changes to the } \\
\text { way or amount } \\
\text { of exercise }\end{array}$ & $\begin{array}{l}\text { 3. Anxiety, } \\
\text { fear, and } \\
\text { uncertainty } \\
\text { about the } \\
\text { future }\end{array}$ & $\begin{array}{l}\text { 4. Having one } \\
\text { member of } \\
\text { staff to speak } \\
\text { to about all } \\
\text { aspects of } \\
\text { care }\end{array}$ & $\begin{array}{l}\text { 5. Being given } \\
\text { information } \\
\text { on the side } \\
\text { effects of } \\
\text { medications }\end{array}$ \\
\hline $\begin{array}{l}\text { Anxiety, fear, or } \\
\text { uncertainty about the } \\
\text { future }\end{array}$ & $\tau \mathrm{b} 0.693^{*}$ & & & & \\
\hline $\begin{array}{l}\text { Feeling down, sad, or } \\
\text { depressed }\end{array}$ & & & $\tau \mathrm{b} 0.693^{*}$ & & \\
\hline $\begin{array}{l}\text { Feeling isolated or } \\
\text { lonely }\end{array}$ & $\tau \mathrm{b} 0.714^{*}$ & & & & \\
\hline $\begin{array}{l}\text { Feeling the need to } \\
\text { hide being unwell }\end{array}$ & $\tau \mathrm{b} 0.601 *$ & & & & \\
\hline $\begin{array}{l}\text { Making changes to } \\
\text { diet }\end{array}$ & & $\tau \mathrm{b} 0.672^{*}$ & & & \\
\hline $\begin{array}{l}\text { Information about } \\
\text { managing the } \\
\text { condition at home }\end{array}$ & & & & $\tau \mathrm{b} 0.617^{*}$ & $\tau \mathrm{b} 0.705^{*}$ \\
\hline $\begin{array}{l}\text { Information about } \\
\text { medications and their } \\
\text { purpose }\end{array}$ & & & & & $\tau \mathrm{b} 0.798^{*}$ \\
\hline $\begin{array}{l}\text { Information on what } \\
\text { to expect after an } \\
\text { operation or procedure }\end{array}$ & & & & & $\tau \mathrm{b} 0.620^{*}$ \\
\hline $\begin{array}{l}\text { Knowing about self- } \\
\text { help resources for } \\
\text { dealing with anxiety or } \\
\text { fears }\end{array}$ & $\tau \mathrm{b} 0.645^{*}$ & & $\tau \mathrm{b} 0.618^{*}$ & & \\
\hline $\begin{array}{l}\text { Primary care staff able } \\
\text { to answer questions }\end{array}$ & & & & $\tau \mathrm{b} 0.629 *$ & \\
\hline $\begin{array}{l}\text { Consistent } \\
\text { information from } \\
\text { healthcare } \\
\text { professionals }\end{array}$ & & & & $\tau \mathrm{b} 0.641^{*}$ & $\tau \mathrm{b} 0.647^{*}$ \\
\hline $\begin{array}{l}\text { Understanding the } \\
\text { advice given by } \\
\text { healthcare } \\
\text { professionals }\end{array}$ & & & & & $\tau \mathrm{b} 0.608^{*}$ \\
\hline
\end{tabular}

C4). The most common option selected was that they are 'too expensive' (32\%, 1903/5966); and 21\% selected they 'do not trust that these technologies will work or help' (1276/5966). The 25\% (1490/5966) who selected 'Other,' noted most frequently that they do not need these devices or are uninterested in using them. While there was no evidence of difference in the use of digital technologies by gender, people under 65 years were significantly more likely to say they use digital technologies $\left(\mathrm{X}^{2} 233.94\right.$ (6) $\mathrm{p}<0.001$; Appendix C5).

\section{Discussion}

The results from this study describe the experiences of a large, self-selected sample of people affected by CVD in the UK. The purpose of the research was to provide insight into the biggest challenges and unmet needs of people affected by CVD, as well as the resources they accessed to help address their support needs.

The top five challenges for people affected by CVD, based on the proportion of people indicating they had a need for 
help, span psychological, physical and care needs (Table 2). The survey results confirm that the key challenges are not restricted to a particular condition, indicated by the minimal variation of the top five difficulties between types of CVD (Table 3).

The most prominent challenges related to emotional wellbeing, with one-quarter of people stating they a had moderate or high need for help with feeling down, sad, or depressed, as well as feelings of anxiety, fear, and uncertainty about the future. Feelings of isolation, loneliness, and the need to hide being unwell from family and friends strongly correlated with these challenges. Further, more than two-thirds received no support to address these needs. It is well documented that people affected by CVD may experience mental ill health; for example, depression is relatively common in patients with heart disease and associated with an increased risk of mortality and morbidity. ${ }^{28}$ Equally, psychological factors, such as stress, can contribute to the development and progression of CVD. ${ }^{29}$ Hopelessness, for example, is "one symptom of depression that appears to have particularly adverse effects on health." 18 Therefore it is vital that attention be given to assessing and addressing the mental wellbeing of people affected by CVD.

The role of exercise in reducing risk of cardiac events ${ }^{30,31}$ and supporting rehabilitation in $\mathrm{CVD}^{32-34}$ is well established in the literature. However, one-quarter of respondents noted that they struggle with making changes to the way and amount they exercise. This correlated with challenges associated with making changes to diet, indicating a struggle with adjusting lifestyle, and the need for support to make these changes. There is evidence that exercise improves psychological symptoms associated with poor health-related quality of life. ${ }^{19}$ Nevertheless, some patients avoid exercise following a cardiac-related diagnosis or event ${ }^{7}$ due to uncertainty about safety and appropriateness and lack of support. 4,35 This was echoed in our study; a number of respondents noted that although they were eager to do physical activity, with limited personalised guidance they were afraid they may push themselves too far, restricting the amount of exercise they were mentally comfortable doing. For people who had received help, the most common source of support that people found beneficial was cardiac rehabilitation.

Continuity of care is a fundamental component of personcentred care, ${ }^{36}$ yet one-fifth of respondents lacked a single point of contact with whom they could discuss their condition or care. The need for a single point of contact was positively correlated with the need for continuity between primary and secondary providers. This included the need for General Practitioners (GPs) or communitybased healthcare staff to be able to answer questions and receiving consistent information from healthcare professionals. Poor coordination can further impact the quality and consistency of information. Respondents reported that having sufficient information about medications and their side-effects was problematic. This is noteworthy, as almost one-half of respondents who needed information about medications and their sideeffects had not received any help. The implications deserve further research, as information can impact adherence. For example, a study examining how negative media coverage may affect people's attitudes and behaviours towards statins found that, concerns about side-effects were associated with poor adherence; conversely, people who had confidence in their GPs had increased willingness to adhere to statins. ${ }^{37}$

Correlations between the top challenges and other needs presented in the survey, suggest that lack of information or knowing how to access alternative resources could exacerbate challenges. For example, the need for help with feeling depressed, or fears about the future was correlated with knowing about self-help resources for dealing with anxiety or fears. Similarly, the need for a single point of contact correlated with needing to be given information about managing the condition at home.

Our study explored the sources of support and information that people with CVD used to help manage their condition. While the majority of respondents stated that they use online resources or digital technologies in day-to-day life, far fewer regularly used these resources to access information about their condition and to help manage their health. Of those who reported using online resources for health, the main reason was to access clinical information about their condition, followed by resources about general health, such as healthy eating and tips on staying in shape.

Key barriers to accessing information and support online included inconsistency of information, trust in the accuracy of information, and accessibility. Respondents stated that it was hard to determine the accuracy and trustworthiness of online information, particularly given the sheer volume of websites available. Some respondents reported concerns about the functionality and accessibility of digital technologies and preferred to seek information and advice in person from medical professionals. There were concerns about the privacy of data captured by digital technologies, such as apps and wearable devices.

\section{Implications}

Overall, our study shows that there is a clear need for a holistic approach to care to support patients' psychological, physical and other support needs. Consistent and timely use of a holistic needs assessment (HNA) tool could ensure people's physical, emotional and social needs are identified and appropriate support provided. HNAs have been introduced as standard practice for all cancer patients in the UK as part of the 
NHS Long Term Plan. ${ }^{38}$ Similar policy for people affected by CVD should be considered.

Our findings indicate the prevalence of mental and emotional ill-health among people affected by CVD, highlighting the need for policy and practice to prioritise strategies in this area. Depressive disorders are among the most common causes of disability (measured as years lived with disability) and are "identified as increasingly important contributors to overall burden across the UK." 3

Our findings further emphasise the need for policy and practice to mitigate the consequent demand for services and the potential negative economic impact. HNAs could support people having their psychological needs identified and to access psychological and emotional wellbeing support. These should take place whenever patient's needs change and support should be adapted. There are a number of studies highlighting the benefits of psychosocial interventions for CVD patients ${ }^{28,39}$ including alternative or complementary approaches such as mindfulness. ${ }^{40,41}$ Referral to psychological services and signposting to charity counselling and advice services could be helpful for patients and carers, and make use of community-based support.

Provision of support to do physical exercise needs improvement. This could mitigate some of the mental health challenges people face, as studies have shown the interplay between physical activity and mental wellbeing. ${ }^{19,42}$ There have been encouraging developments in this area since we conducted our study, with the NHS Long Term Plan prioritising cardiac rehabilitation, ${ }^{38}$ particularly for patients with heart failure and heart valve disease. ${ }^{43}$ However, our results indicate that for this to be impactful, people need personalised guidance about the type and amount of exercise that is appropriate for them. Furthermore, access to cardiac rehabilitation and other forms of exercise support should be available for all condition types, as exercise was present in the top five challenges for all conditions in our study.

Individuals living with CVD are routinely encouraged to engage in self-care as part of their daily disease management. Yet, there is a clear need for clarity and guidance from reliable sources, such as healthcare professionals or reputable organisations, to support people with navigating the overwhelming volume of online information and resources, and to understand which are appropriate and accurate. Our results mirrored other studies that reported barriers to utilising online health information, particularly studies examining choice in healthcare. ${ }^{44,45}$ As Hibbard and Peters noted, "having an abundance of information does not always translate into it being used." 46 The accessibility of information is crucial to ensure intentions are not undermined. A challenge is to avoid simply overloading patients with information and to ensure it is presented and targeted in a meaningful and digestible format. The design should take into consideration the range of user skills and literacy. Information producers and providers should understand and utilise existing research to ensure an evidence-based approach is used to design information and platforms (such as websites) to enhance the successful use of information. Drawing on the principles of person-centred care, patients and carers should be decision makers in the design of support packages to ensure they are fit for purpose.

The role of third sector organisations in addressing some of these unmet needs through, for example sign-posting, advocacy, and provision of up-to-date information and resources, should be explored. Improved coordination between healthcare providers could help standardise messaging and support packages. Interactions with healthcare professionals are valued, and results highlight the need for personalisation of advice and information. Thus, online resources and digital technologies should be used to complement and not replace tailored advice and support provided to patients.

\section{Limitations}

While this was a large study, the respondents to the questionnaire self-selected, and in some cases came from an unknown population through online advertisement. As it was an open link (i.e., no login details were required), the email and survey link could be forwarded to people not on the mailing list. Therefore, the sample may not be representative of the population of people affected by CVD. Furthermore, the effects of CVD on a respondent were self-reported and cannot be verified.

\section{Conclusions}

There have been major advancements in the prevention and treatment of CVD, reflected in substantial reductions of premature deaths. However, CVD remains a significant burden, with reports indicating an increase in treatment and hospital admissions in the UK. ${ }^{2}$ As death rates decrease, people affected by CVD continue to live with these diseases and the associated challenges, long-term. Our study provides evidence for healthcare providers, voluntary sector organisations (such as the British Heart Foundation), regulators, and national bodies about where improvement initiatives are required, and resources should be prioritised to mitigate the increased burden due to morbidity. Receiving a diagnosis for CVD or living with risk factors can have psychological, social, and physical consequences that require considerable adjustments in an individual's life. Yet many people do not receive adequate assistance. Fragmented care and variable access to information and support, compounds these issues. Providing holistic care requires the acknowledgement of psychological needs and access to services, alongside support for physical challenges. Accurate information 
from reliable sources is needed: organisations should work together to decrease the noise and inconsistency. The key challenges are not restricted to a particular condition, indicating that interventions could benefit numerous patient groups, rather than focusing on a single condition. Empowering people to manage their condition and the consequential impacts by providing the evidence-informed tools, information, and support is crucial to improve quality of life and will have knock-on effects for the healthcare system as a whole.

\section{References}

1. British Heart Foundation. Heart statistics. Published 2019. Accessed October 15, 2019.

https://www.bhf.org.uk/what-we-do/ourresearch/heart-statistics

2. Bhatnagar P, Wickramasinghe K, Wilkins E, Townsend N. Trends in the epidemiology of cardiovascular disease in the UK. Heart. 2016;102(24):1945-1952. doi:10.1136/heartjnl-2016309573

3. Steel N, Ford JA, Newton JN, et al. Changes in health in the countries of the UK and 150 English Local Authority areas 1990-2016: A systematic analysis for the Global Burden of Disease Study 2016. The Lancet. 2018;392(10158):1647-1661. doi:10.1016/S01406736(18)32207-4

4. Cunningham MA, Swanson V, Pappas E, O'Carroll RE, Holdsworth RJ. Illness Beliefs and Walking Behavior After Revascularization for Intermittent Claudication: A QUALITATIVE STUDY. Journal of Cardiopulmonary Rehabilitation and Prevention. 2014;34(3):195-201. doi:10.1097/HCR.0000000000000046

5. Rejeski W, Spring B, Domanchuk K, et al. A groupmediated, home-based physical activity intervention for patients with peripheral artery disease: Effects on social and psychological function. J Transl Med. 2014;12(1):29. doi:10.1186/1479-5876-12-29

6. Olin JW, White CJ, Armstrong EJ, Kadian-Dodov D, Hiatt WR. Peripheral Artery Disease: Evolving role of exercise, medical therapy and endovascular options. Journal of the American College of Cardiology. 2016;67(11):1338-1357. doi:10.1016/j.jacc.2015.12.049

7. Longmuir PE, Brothers JA, de Ferranti SD, et al. Promotion of Physical Activity for Children and Adults With Congenital Heart Disease: A Scientific Statement From the American Heart Association. Circulation. 2013;127(21):2147-2159. doi:10.1161/CIR.0b013e318293688f

8. Morrison ML, Sands AJ, McCusker CG, et al. Exercise training improves activity in adolescents with congenital heart disease. Heart. 2013;99(15):11221128. doi:10.1136/heartjnl-2013-303849
9. Cole JA, Smith SM, Hart N, Cupples ME. Do practitioners and friends support patients with coronary heart disease in lifestyle change? A qualitative study. BMC Fam Pract. 2013;14(1):126. doi:10.1186/1471-2296-14-126

10. Eslami B, Sundin Ö, Macassa G, Khankeh HR, Soares JJF. Anxiety, depressive and somatic symptoms in adults with congenital heart disease. Journal of Psychosomatic Research. 2013;74(1):49-56. doi:10.1016/j.jpsychores.2012.10.006

11. Lee KS, Lennie TA, Yoon JY, Wu J-R, Moser DK. Living Arrangements Modify the Relationship Between Depressive Symptoms and Self-care in Patients With Heart Failure: The Journal of Cardiovascular Nursing. 2017;32(2):171-179. doi:10.1097/JCN.0000000000000327

12. Holden RJ, Schubert CC, Mickelson RS. The patient work system: An analysis of self-care performance barriers among elderly heart failure patients and their informal caregivers. Applied Ergonomics. 2015;47:133150. doi:10.1016/j.apergo.2014.09.009

13. Browne S, Macdonald S, May CR, Macleod U, Mair FS. Patient, Carer and Professional Perspectives on Barriers and Facilitators to Quality Care in Advanced Heart Failure. Harris F, ed. PLoS ONE. 2014;9(3):e93288. doi:10.1371/journal.pone.0093288

14. Goosens E, Van Deyk K, Zupancic N, Budts W, Moons P. Effectiveness of structured patient education on the knowledge level of adolescents and adults with congenital heart disease. Eur J Cardiovasc Nurs. 2014;13(1):63-70. doi:doi:10.1177/1474515113479231

15. Mackie AS, Islam S, Magill-Evans J, et al. Healthcare transition for youth with heart disease: A clinical trial. Heart. 2014;100:1113-1118. doi:http:/ /dx.doi.org/10.1136/heartjnl-2014-305748

16. Bhattacharyya M, Stevenson F, Walters K. Exploration of the psychological impact and adaptation to cardiac events in South Asians in the UK: a qualitative study. BMJ Open. 2016;6(7):e010195. doi:doi: 10.1136/bmjopen-2015-010195

17. Reeves MJ, Prager M, Fang J, Stamplecoski M, Kapral MK. Impact of Living Alone on the Care and Outcomes of Patients With Acute Stroke. Stroke. 2014;45(10):3083-3085. doi:10.1161/STROKEAHA.114.006520

18. Anda R, Williamson D, Jones D, et al. Depressed Affect, Hopelessness, and the Risk of Ischemic Heart Disease in a Cohort of U.S. Adults. Epidemiology. 1993;4(4):285.

19. Aidar FJ, Garrido ND, Silva AJ, Reis VM, Marinho DA, de Oliveira RJ. Effects of aquatic exercise on depression and anxiety in ischemic stroke subjects. Health. 2013;05(02):222-228. doi:10.4236/health.2013.52030

20. Staniute M, Brozaitiene J, Bunevicius R. Effects of Social Support and Stressful Life Events on Health- 
Related Quality of Life in Coronary Artery Disease Patients: The Journal of Cardiovascular Nursing. 2013;28(1):83-89. doi:10.1097/JCN.0b013e318233e69d

21. Steptoe A, Kivimäki M. Stress and Cardiovascular Disease: An Update on Current Knowledge. Annual Review of Public Health. 2013;34(1):337-354. doi:10.1146/annurev-publhealth-031912-114452

22. Dickson VV, Buck H, Riegel B. Multiple Comorbid Conditions Challenge Heart Failure Self-Care by Decreasing Self-Efficacy: Nursing Research. 2013;62(1):2-9. doi:10.1097/NNR.0b013e31827337b3

23. Blair J, Volpe M, Aggarwal B. Challenges, Needs, and Experiences of Recently Hospitalized Cardiac Patients and Their Informal Caregivers: The Journal of Cardiovascular Nursing. 2014;29(1):29-37. doi:10.1097/JCN.0b013e3182784123

24. Franco M, Cooper RS, Bilal U, Fuster V. Challenges and Opportunities for Cardiovascular Disease Prevention. Am J Med. 2011;124(2):95-102. doi:10.1016/j.amjmed.2010.08.015

25. McClellan M, Brown N, Califf RM, Warner JJ. Call to Action: Urgent Challenges in Cardiovascular Disease: A Presidential Advisory From the American Heart Association. Circulation. 2019;139(9). doi:10.1161/CIR.0000000000000652

26. Zanaboni P, Ngangue P, Mbemba GIC, Schopf TR, Bergmo TS, Gagnon M-P. Methods to Evaluate the Effects of Internet-Based Digital Health Interventions for Citizens: Systematic Review of Reviews. J Med Internet Res. 2018;20(6):e10202. doi:10.2196/10202

27. Bunn JA, Navalta JW, Fountaine CJ. Current State of Commercial Wearable Technology in Physical Activity Monitoring 2015-2017. Published online 2018:13.

28. Richards SH, Anderson L, Jenkinson CE, et al. Psychological interventions for coronary heart disease: Cochrane systematic review and meta-analysis. Eur J Prev Cardiolog. 2018;25(3):247-259. doi:10.1177/2047487317739978

29. Kivimäki M, Steptoe A. Effects of stress on the development and progression of cardiovascular disease. Nature Reviews Cardiology. 2018;15:215-229. doi:https://doi.org/10.1038/nrcardio.2017.189

30. Alexander GK, Innes KE, Selfe TK, Brown CJ. "More than I expected": Perceived benefits of yoga practice among older adults at risk for cardiovascular disease. Complementary Therapies in Medicine. 2013;21(1):14-28. doi:10.1016/j.ctim.2012.11.001

31. Krishna BH, Pal P, Pal G, et al. Effect of Yoga Therapy on Heart Rate, Blood Pressure and Cardiac Autonomic Function in Heart Failure. JCDR. 2014;8(1):14-16. doi:10.7860/JCDR/2014/7844.3983

32. Anderson L, Oldridge N, Thompson DR, et al. Exercise-Based Cardiac Rehabilitation for Coronary Heart Disease. Journal of the American College of Cardiology. 2016;67(1):1-12. doi:10.1016/j.jacc.2015.10.044
33. Lan C, Chen S-Y, Wong M-K, Lai JS. Tai Chi Chuan Exercise for Patients with Cardiovascular Disease. Evidence-Based Complementary and Alternative Medicine. 2013;2013:1-9. doi:10.1155/2013/983208

34. Sagar VA, Davies EJ, Briscoe S, et al. Exercise-based rehabilitation for heart failure: Systematic review and meta-analysis. Open Heart. 2015;2(1):e000163. doi:10.1136/openhrt-2014-000163

35. Hirani SP. Patients' beliefs about their cardiovascular disease. Heart. 2005;91(9):1235-1239. doi:10.1136/hrt.2003.025262

36. Picker. Principles of Person Centred Care. Principles of Person Centred Care. Accessed May 10, 2020. https://www.picker.org/about-us/picker-principlesof-person-centred-care/

37. Bohan H, van Doom T, Witiwicki C, Coulter A. Perceptions of Statins: Research with Patients, GPs and Cardiologists. Picker; 2016. Accessed May 12, 2020. https://www.picker.org/wpcontent/uploads/2016/07/P2941-BHFStatins_Final-Report_Publication.pdf

38. NHS. The NHS long term plan. Published 2019. Accessed May 10, 2020. https://www.longtermplan.nhs.uk/

39. Donders P. The psychological impact of a cardiovascular disease. Neth Heart J. 2005;13(4):160.

40. O’Doherty V, Carr A, McGrann A, et al. A Controlled Evaluation of Mindfulness-Based Cognitive Therapy for Patients with Coronary Heart Disease and Depression. Mindfulness. 2015;6(3):405416. doi:10.1007/s12671-013-0272-0

41. Parswani M, Sharma M, Iyengar S. Mindfulness-based stress reduction program in coronary heart disease: A randomized control trial. Int J Yoga. 2013;6(2):111. doi:10.4103/0973-6131.113405

42. Salman A, Sellami M, AL-Mohannadi AS, Chun S. The Associations between Mental Well-Being and Adherence to Physical Activity Guidelines in Patients with Cardiovascular Disease: Results from the Scottish Health Survey. IJERPH. 2019;16(19):3596. doi:10.3390/ijerph16193596

43. NHS England. Cardiovascular disease. Accessed June 6, 2020.

https://www.england.nhs.uk/ourwork/clinicalpolicy/cvd/

44. Henwood F, Wyatt S, Hart A, Smith J. Turned on or turned off? Accessing health information on the Internet. Scandinavian Journal of Information Systems. 2002;14(2):4.

45. Damman OC, Hendriks M, Rademakers J, Delnoij DM, Groenewegen PP. How do healthcare consumers process and evaluate comparative healthcare information? A qualitative study using cognitive interviews. BMC Public Health. 2009;9(1):423. doi:10.1186/1471-2458-9-423

46. Hibbard JH, Peters E. Supporting Informed Consumer Health Care Decisions: Data Presentation 
Approaches that Facilitate the Use of Information in

Choice. Annu Rev Public Health. 2003;24(1):413-433.

doi:10.1146/annurev.publhealth.24.100901.141005 


\section{Appendix A: List of challenges in questionnaire}

\section{Physical challenges}

- Feeling weak/ lack of energy

- Work around the home (e.g. cleaning, cooking, eating, washing)

- Not being able to do the things you used to, such as driving

- Support with work such as reducing hours or stopping work

- Accessibility in public spaces for people with limited mobility (for e.g. lifts or ramps)

- Activities related to providing care for someone else

- Making changes to your diet/ following a healthy diet

- Making changes to the way or amount you exercise

\section{Emotional or psychological challenges}

- Anxiety, fear, or uncertainty about the future

- Feeling down, sad, or depressed

- Feeling the need to hide being unwell from family, friends, and colleagues

- Feeling isolated or lonely

- Knowing about self-help resources for dealing with anxiety or fears

- Having access to professional counselling (e.g. psychologist, social worked, counsellor, specialist nurse) if you, family, or friends need it

- Colleagues and managers being understanding of the impact of the condition

- Maintaining a good quality of life

- $\quad$ Providing care or support to someone close to you

\section{Medical, information or support challenges}

- Your needs met by the care you received in the community following discharge from hospital or in between hospital visits

- GPs or other primary or community-based healthcare staff being able to answer your questions, and in a way you could understand

- Having access to NHS rehabilitation services

- Having one member of staff with whom you can talk to about all aspects of the condition, treatment and care (such as the same GP, consultant, or specialist nurse)

- Being given information on what to expect after an operation or procedure

- Being given information about medications and their purpose

- Being given information on the side effects of medications

- Being given information about managing the condition at home

- Receiving consistent information from healthcare professionals

- Understanding the advice given by healthcare professionals

- Being given information about other resources you can use to get more information about the condition, such as websites or charities

- Support when moving from children's services to adult services

- Being given guidance on how much exercise or work can be done

- Being given information about other resources you can use to help manage your condition, such as Apps, wearable technologies (e.g. Fitbit), or websites

- Being given information about other non-medical resources you can access

- Having access to support groups

- Support groups that accept or provide support for carers, friends, or family

- Having access to online support groups 


\section{Appendix B: Respondent characteristics}

The respondents were roughly equal in number for gender, typically aged 55 and over, and most people affected by CVD had a heart or circulatory condition themselves.

Table B1. Respondent characteristics for the online questionnaire, frequency of response selected and percentages of that response (single selection responses unless marked).

\begin{tabular}{|c|c|c|}
\hline Characteristic & $\begin{array}{l}\text { Number of } \\
\text { responses }\end{array}$ & Percentage \\
\hline \multicolumn{3}{|l|}{ Gender } \\
\hline Male & 4800 & $51 \%$ \\
\hline Female & 4635 & $49 \%$ \\
\hline Other & 4 & $<1 \%$ \\
\hline Prefer not to say & 22 & $<1 \%$ \\
\hline Responses & 9461 & \\
\hline unanswered & 4424 & \\
\hline \multicolumn{3}{|l|}{ Age } \\
\hline $16-18$ & 2 & $<1 \%$ \\
\hline $19-24$ & 10 & $<1 \%$ \\
\hline $25-34$ & 85 & $1 \%$ \\
\hline $35-44$ & 221 & $2 \%$ \\
\hline $45-54$ & 943 & $10 \%$ \\
\hline $55-64$ & 2614 & $28 \%$ \\
\hline $65-74$ & 3868 & $41 \%$ \\
\hline $75-84$ & 1512 & $16 \%$ \\
\hline $85+$ & 217 & $2 \%$ \\
\hline Responses & 9472 & \\
\hline unanswered & 4413 & \\
\hline \multicolumn{3}{|l|}{ Impact of CVD } \\
\hline Had heart or circulatory condition (CVD) & 4696 & $49 \%$ \\
\hline Had a risk factor & 3088 & $32 \%$ \\
\hline Cared for someone with a heart or circulatory condition & 515 & $5 \%$ \\
\hline Cared for someone with a risk factor & 218 & $2 \%$ \\
\hline Other & 1012 & $11 \%$ \\
\hline Responses & 9529 & \\
\hline unanswered & 4356 & \\
\hline \multicolumn{3}{|l|}{ Previous knowledge of, or engagement with, the BHF (multiple select) } \\
\hline Used their materials such as booklets, pamphlets or the website & 6798 & $73 \%$ \\
\hline Give financial donations, or charity shop donations & 5961 & $64 \%$ \\
\hline Heard of BHF but have never used any of their services or materials & 1228 & $13 \%$ \\
\hline Participate in BHF events & 458 & $5 \%$ \\
\hline Volunteer or involved in committees, etc. & 206 & $2 \%$ \\
\hline Had not heard of the BHF before today & 182 & $2 \%$ \\
\hline Responses & 9352 & \\
\hline unanswered & 4533 & \\
\hline
\end{tabular}




\section{Appendix C: Supplementary results}

\section{C1. Resources used for information or to help manage health, 7469 respondents, multiple select}

\begin{tabular}{|l|l|l|}
\hline Usage & $\begin{array}{l}\text { Number of } \\
\text { responses }\end{array}$ & Percentage \\
\hline $\begin{array}{l}\text { Websites to get information about the condition or diagnosis (e.g. clinical } \\
\text { information) }\end{array}$ & 6073 & $81 \%$ \\
\hline $\begin{array}{l}\text { Other online resources to help manage general health such as healthy eating, } \\
\text { recipe websites or tips to stay in shape }\end{array}$ & 4882 & $65 \%$ \\
\hline Websites to get information on how to manage the condition at home & 4124 & $55 \%$ \\
\hline Websites to get information about different treatment options & 4031 & $54 \%$ \\
\hline Health Apps, such as a calorie counter, a steps counter, App or salt calculator & 2452 & $33 \%$ \\
\hline Online resources to get information about mental health and well-being & 1940 & $26 \%$ \\
\hline Online exercise programmes (such as exercise videos) & 1427 & $19 \%$ \\
\hline $\begin{array}{l}\text { Internet forums or messaging boards to share or receive information about your } \\
\text { health or condition }\end{array}$ & 1173 & $16 \%$ \\
\hline Online support groups & 762 & $10 \%$ \\
\hline Other online help lines or 'Live Chat' options to get help or information & 400 & $5 \%$ \\
\hline None of the above/ I do not use online resources for health & 389 & $5 \%$ \\
\hline Other & 132 & $2 \%$ \\
\hline Total Respondents & 7469 & \\
\hline
\end{tabular}

C2. Use of online resources by age and gender

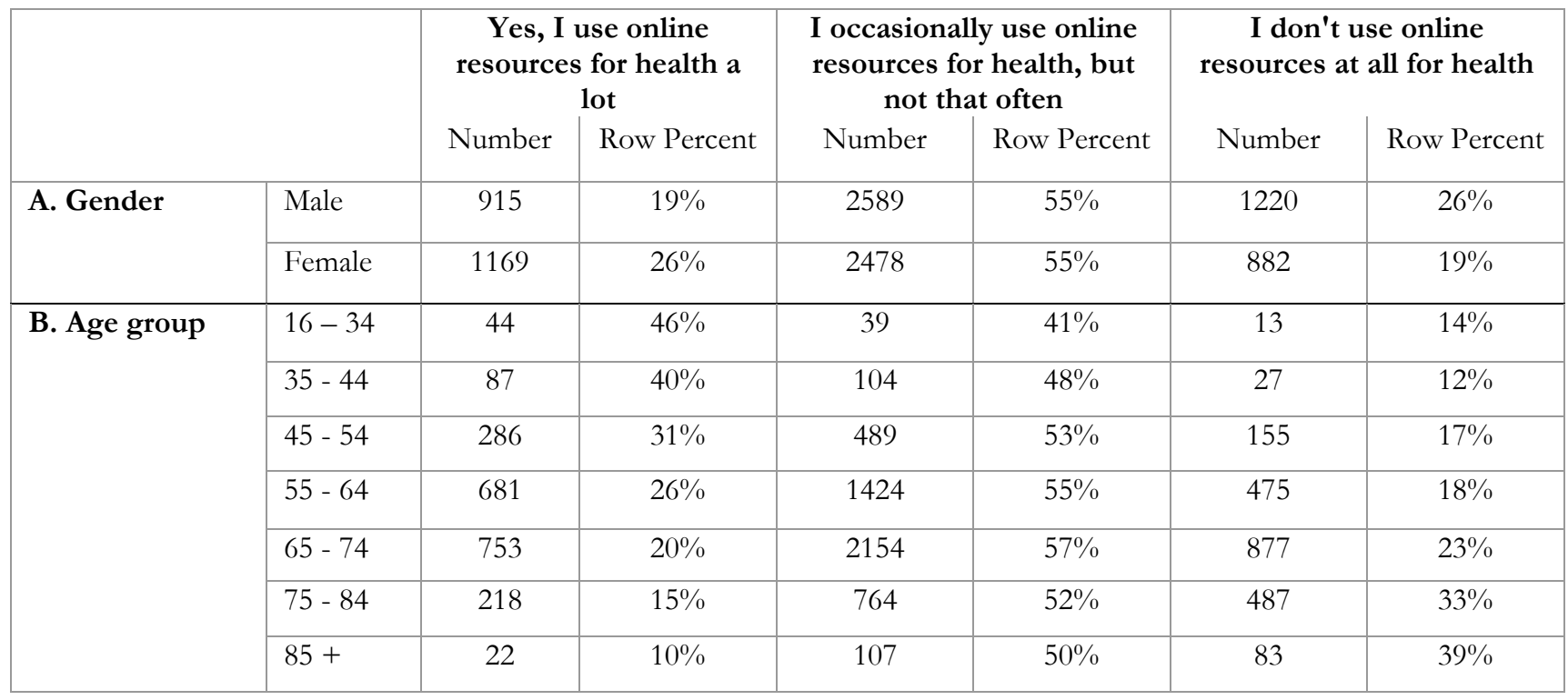


C3. Reasons for not using online or digital technologies, 4553 respondents, multiple select

\begin{tabular}{|c|c|c|}
\hline Reason & $\begin{array}{l}\text { Number of } \\
\text { responses }\end{array}$ & Percentage \\
\hline Different websites give different information or advice & 1872 & $41 \%$ \\
\hline I don't need any more information or help & 1273 & $28 \%$ \\
\hline I don't trust the information online & 921 & $20 \%$ \\
\hline There is too much health information online / I don't know where to start looking & 839 & $18 \%$ \\
\hline I have privacy and security concerns & 666 & $15 \%$ \\
\hline Looking at or reading the information online makes me worried or scared & 652 & $14 \%$ \\
\hline Other & 453 & $10 \%$ \\
\hline I never get around to looking at it & 372 & $8 \%$ \\
\hline I don't want to know anything more about the condition or how to manage it & 268 & $6 \%$ \\
\hline I don't know how to use digital resource & 194 & $4 \%$ \\
\hline I want to but I don't understand how to use the resources & 165 & $4 \%$ \\
\hline I don't have access to digital resources & 55 & $1 \%$ \\
\hline I am physically unable to use the equipment needed to use online resources & 37 & $1 \%$ \\
\hline Total Respondents & 4553 & \\
\hline
\end{tabular}

C4. Reasons for not using digital technologies or devices, 5966 respondents, multiple select

\begin{tabular}{|c|c|c|}
\hline Reason & $\begin{array}{l}\text { Number of } \\
\text { responses }\end{array}$ & Percentage \\
\hline They are too expensive & 1903 & $32 \%$ \\
\hline Other & 1490 & $25 \%$ \\
\hline I don't trust that they work or will help & 1276 & $21 \%$ \\
\hline There is too much choice and I don't know which is the best & 1089 & $18 \%$ \\
\hline I do not know what is available & 1072 & $18 \%$ \\
\hline I have privacy or security concerns (e.g. amount of personal data they capture) & 903 & $15 \%$ \\
\hline I don't know how to use them & 817 & $14 \%$ \\
\hline Total Respondents & 5966 & \\
\hline
\end{tabular}

C5. Respondents using digital technologies or devices, such as wearable technologies, by age group

\begin{tabular}{|c|c|c|c|c|}
\hline \multirow[t]{3}{*}{ Age group } & \multicolumn{4}{|c|}{ Using any digital technologies or devices } \\
\hline & \multicolumn{2}{|c|}{ Yes } & \multicolumn{2}{|c|}{ No } \\
\hline & $\begin{array}{c}\text { Number of } \\
\text { responses }\end{array}$ & Row Percentage & $\begin{array}{c}\text { Number of } \\
\text { responses }\end{array}$ & Row Percentage \\
\hline $16-34$ & 37 & $39 \%$ & 58 & $61 \%$ \\
\hline $35-44$ & 98 & $45 \%$ & 121 & $55 \%$ \\
\hline $45-54$ & 408 & $44 \%$ & 523 & $56 \%$ \\
\hline $55-64$ & 1024 & $40 \%$ & 1565 & $60 \%$ \\
\hline $65-74$ & 1239 & $32 \%$ & 2581 & $68 \%$ \\
\hline $75-84$ & 306 & $20 \%$ & 1191 & $80 \%$ \\
\hline $85+$ & 42 & $20 \%$ & 167 & $80 \%$ \\
\hline
\end{tabular}

